\title{
Comparative proteomics of Rhizopus delemar ATCC 20344 unravels the role of amino acid catabolism in fumarate accumulation
}

Dorett I Odoni ${ }^{1}$, Juan A Tamayo-Ramos ${ }^{1}{ }^{\text {, }}$, Jasper Sloothaak ${ }^{1}$, Ruben G A van Heck ${ }^{1}$, Vitor A P Martins dos Santos $^{1,2}$ ， Leo H de Graaff ${ }^{1}$ ， Maria Suarez-Diez ${ }^{1}$ ， Peter J Schaap ${ }^{\text {corresp. } 1}$

1 Laboratory of Systems and Synthetic Biology, Wageningen University and Research, Wageningen, The Netherlands

2 LifeGlimmer GmBH, Berlin, Germany

Corresponding Author: Peter J Schaap

Email address: peter.schaap@wur.nl

The filamentous fungus Rhizopus delemar naturally accumulates relatively high amounts of fumarate. Although the culture conditions that increase fumarate yields are well established, the network underlying the accumulation of fumarate is not yet fully understood. We set out to increase the knowledge about fumarate accumulation in $R$. delemar. To this end, we combined a transcriptomics and proteomics approach to identify key metabolic pathways involved in fumarate production in $R$. delemar, and propose that a substantial part of the fumarate accumulated in $R$. delemar during nitrogen starvation results from the urea cycle due to amino acid catabolism. 
1 Comparative proteomics of Rhizopus delemar ATCC 20344

2 unravels the role of amino acid catabolism in fumarate

3 accumulation

4 Dorett I Odoni $^{1+}$, Juan A Tamayo-Ramos ${ }^{1+}$, Jasper Sloothaak ${ }^{1}$, Ruben G A van Heck ${ }^{1}$,

5 Vitor A P Martins dos Santos ${ }^{1,2}$, Leo H de Graaff ${ }^{\dagger}$, Maria Suarez-Diez ${ }^{1}$ and Peter J

6 Schaap $^{1}$

$7{ }^{1}$ Laboratory of Systems and Synthetic Biology, Wageningen University and Research,

8 Stippeneng 4, 6708 WE Wageningen, the Netherlands

$9 \quad 2$ LifeGlimmer GmBH, Berlin, Germany

10

11

12

$13{ }^{+}$Equal contributions

$14 \dagger$ Deceased 16 October 2016

15

16 Corresponding author:

17 Peter J Schaap ${ }^{1}$

18

19

20 Email address:

21

PJS: peter.schaap@wur.nl 


\section{Abstract}

23 The filamentous fungus Rhizopus delemar naturally accumulates relatively high amounts of

24 fumarate. Although the culture conditions that increase fumarate yields are well established, the

25 network underlying the accumulation of fumarate is not yet fully understood. We set out to

26 increase the knowledge about fumarate accumulation in $R$. delemar. To this end, we combined a

27 transcriptomics and proteomics approach to identify key metabolic pathways involved in

28 fumarate production in $R$. delemar, and propose that a substantial part of the fumarate

29 accumulated in $R$. delemar during nitrogen starvation results from the urea cycle due to amino

30 acid catabolism.

\section{Introduction}

33 Fumarate, a dicarboxylic acid, is an important building block chemical for a number of high-

34 value chemicals and materials. Amongst the microorganisms identified to be natural fumarate

35 producers, the filamentous fungus Rhizopus delemar has the highest product yields [1]. The most

36 important factor influencing fumarate production in $R$. delemar is a high carbon:nitrogen ratio;

37 extracellular fumarate accumulation happens after the growth phase, and especially when the

38 nitrogen in the medium has been depleted $[2,3]$. The choice of nitrogen source has been reported

39 to influence the final fumarate yield $[1,4,5]$, but so far no consensus on these influences has been

40 reached. Another important factor influencing fumarate production in $R$. delemar is oxygen

41 availability $[1,6]$. Under fumarate producing conditions, $R$. delemar forms ethanol and other

42 undesired fermentation by-products [7], directing carbon away from fumarate (Fig. 1). Higher

43 oxygen levels limit the amount of ethanol produced, and thus lead to higher fumarate yields.

44 Fumarate production by fermentation has been extensively reviewed $[8,9]$. 


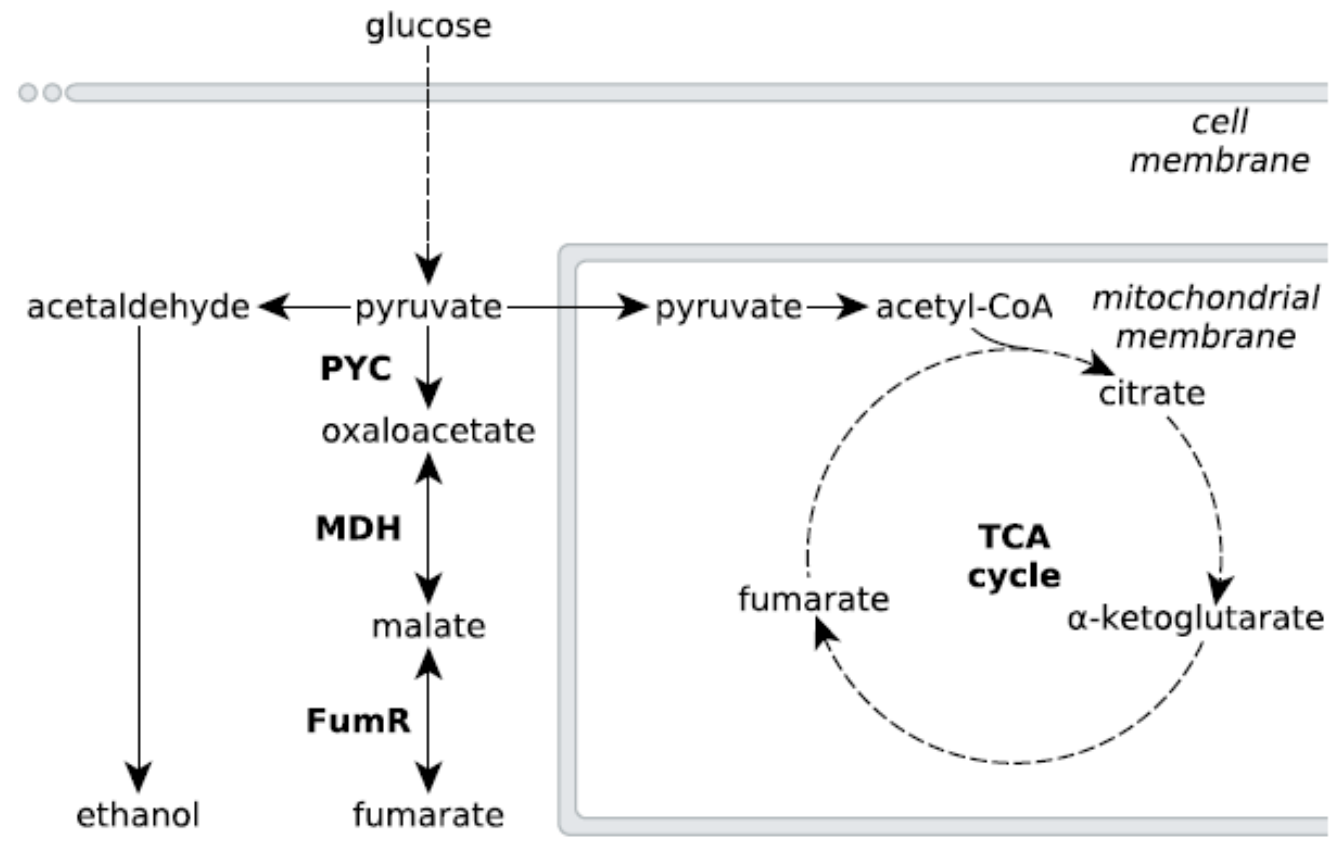

Figure 1. Metabolic pathways involved in fumarate metabolism in $R$. delemar.

Metabolic flux of $R$. delemar is predominantly directed towards fumarate (under aerobic

conditions) or ethanol (under anaerobic conditions). The enzymes of the reductive TCA cycle are indicated in the scheme: PYC = pyruvate carboxylase, $\mathrm{MDH}=\mathrm{L}-\mathrm{malate}$ dehydrogenase and

$51 \quad$ FumR $=$ fumarase.

Although the culture conditions that increase fumarate accumulation in $R$. delemar are well established, natural product titers still cannot compete with chemical fumarate synthesis. To increase the amount of fumarate produced, $R$. delemar has been genetically modified [10-12], but the occurrence of an ancestral whole-genome duplication as well as more recent geneduplication events complicate the genetic engineering of $R$. delemar [13]. A more promising approach for biological fumarate production would thus be rewiring the metabolism of a genetically more amenable cell-factory, based on $R$. delemar fumarate synthesis pathways. 
61 Metabolic engineering approaches to increase fumarate production in microbial cell-factories

62 that do not naturally accumulate high amounts of fumarate would greatly benefit from an in-

63 depth understanding of the underlying metabolic pathways that affect the accumulation of

64 fumarate in the natural fumarate producer $R$. delemar, as well as possible causes for this

65 accumulation. Fumarate can be found as an intermediate in various different metabolic

66 subsystems, and a number of pathways have been investigated for fumarate production in several

67 microbial cell-factories such as Saccharomyces cerevisiae, Torulopsis glabrata, Scheffersomyces

68 stipitis and Escherichia coli [14-22]. Despite the large number of pathways leading to fumarate,

69 the current consensus is that the reductive route of the TCA cycle in the cytosol is responsible for

70 fumarate accumulation in $R$. delemar [23-27]. The reductive TCA cycle comprises pyruvate

71 carboxylase (PYC), L-malate dehydrogenase (MDH) and fumarase (FumR), in which pyruvate is

72 consecutively converted to oxaloacetate, L-malate and fumarate (Fig. 1).

74 A controversial aspect of this pathway model is FumR. While overexpression of $p y c$ and $m d h$

75 gave the expected increase of fumarate in $R$. delemar and Saccharomyces cerevisiae $[11,20]$,

76 overexpression of fumR in $R$. delemar as well as the introduction of fumR in $S$. cerevisiae and $A$.

77 niger was reported to result in more L-malate rather than the accumulation of fumarate

$78[12,20,28]$. There has been debate about the role of FumR in fumarate accumulation, discussed

79 by Meussen et al. [10]. In summary, the reaction kinetics of FumR favour the conversion of

80 fumarate to L-malate rather than the reverse direction, and FumR activity of acid-producing

81 mycelium is completely blocked in the presence of $2 \mathrm{mM}$ fumarate (note that the data on FumR 
82 inhibition have never been published, but that this finding is cited by $[3,10])$. This suggests the

83 presence of an alternative pathway that is responsible for fumarate accumulation in $R$. delemar.

85 In this study, we aim to provide a holistic overview of the pathways involved in fumarate accumulation in the natural fumarate producer $R$. delemar. To this end, we cultured the $R$. delemar strain ATCC 20344 under nitrogen starvation conditions, and varied oxygen availability to induce high (aerobic) and low (anaerobic) fumarate production. Combining transcriptomic and proteomic data obtained from the two conditions, we revealed the relationship between nitrogen metabolism and fumarate accumulation in $R$. delemar, mediated by the urea cycle.

\section{Materials and Methods}

\section{Strains, media and culture conditions}

93 We selected the $R$. delemar strain ATCC 20344 (a kind gift from Adrie J.J. Straathof, Delft

94 University of Technology) to study fumarate production. Note that $R$. delemar is more

95 commonly known as R. oryzae (also Rhizopus nigricans and Rhizopus arrhizus) [29]. Depending

96 on the organic acid produced when grown on D-glucose, it is divided into two phylogenetically

97 distinct types: type I strains, which produce primarily L-lactate, and type II strains, which

98 produce mainly fumarate and L-malate [30]. Complete medium agar plates containing $0.3 \%$

$99(\mathrm{w} / \mathrm{v})$ yeast extract, $0.3 \%(\mathrm{w} / \mathrm{v})$ malt extract, $0.3 \%(\mathrm{w} / \mathrm{v})$ peptone, $2 \%(\mathrm{w} / \mathrm{v})$ glycerol, and $2 \%$

$100(\mathrm{w} / \mathrm{v})$ agar were used to generate spores. Mycelial biomass was produced using pre-culture

101 medium containing $1 \%(\mathrm{w} / \mathrm{v})$ D-glucose, $0.21 \%(\mathrm{w} / \mathrm{v})$ urea, $0.06 \%(\mathrm{w} / \mathrm{v}) \mathrm{KH}_{2} \mathrm{PO}_{4}, 0.05 \%(\mathrm{w} / \mathrm{v})$

$102 \mathrm{MgSO}_{4} \cdot 7 \mathrm{H}_{2} \mathrm{O}$ and $0.0018 \%(\mathrm{w} / \mathrm{v}) \mathrm{ZnSO}_{4} \cdot 7 \mathrm{H}_{2} \mathrm{O}$. Approximately $10^{6}$ spores $/ \mathrm{mL}$ were inoculated in

103 1L Erlenmeyer flasks containing $500 \mathrm{~mL}$ of pre-culture medium and cultivations were carried

104 out at $35^{\circ} \mathrm{C}$ and $250 \mathrm{rpm}$ for 24 hours. The mycelium obtained was washed with demineralized 
105 water and transferred $(\approx 25 \mathrm{~g}$ of wet biomass) to production medium, which contained $10 \%(\mathrm{w} / \mathrm{v})$

106 D-glucose, $0.06 \%(\mathrm{w} / \mathrm{v}) \mathrm{KH}_{2} \mathrm{PO}_{4}, 0.05 \%(\mathrm{w} / \mathrm{v}) \mathrm{MgSO}_{4} \cdot 7 \mathrm{H}_{2} \mathrm{O}, 0.0018 \%(\mathrm{w} / \mathrm{v}) \mathrm{ZnSO}_{4} \cdot 7 \mathrm{H}_{2} \mathrm{O}$, and

$1071 \%(\mathrm{w} / \mathrm{v}) \mathrm{CaCO}_{3}$ (used as a neutralizing agent). Batch fermentations were performed at $35^{\circ} \mathrm{C}$ and

$108600 \mathrm{rpm}$ in $2.5 \mathrm{~L}$ fermentors (Applikon, Schiedam, the Netherlands), with a working volume of

109 1.75 L. Antifoam 204 was added to each fermentor $(85 \mu \mathrm{L})$. The fermentation medium was

110 aerated with $1.0 \mathrm{~L} / \mathrm{L}$ min, either with filtered air or $\mathrm{N}_{2}$ gas.

111

112 Metabolite analysis using HPLC

113 Extracellular metabolite concentrations were determined by high-performance liquid

114 chromatography (HPLC). A Thermo Accela HPLC, equipped with a Shodex KC-811 column,

115 and coupled to a refractive index detector (Spectrasystem RI-150, sample frequency 5.00032Hz)

116 and a UV-VIS detector (Spectrasytem UV1000, $\lambda=210 \mathrm{~nm}$ ), was used. Separations were

117 performed by isocratic elution with $0.01 \mathrm{~N} \mathrm{H}_{2} \mathrm{SO}_{4}$ at a flow rate of $0.8 \mathrm{~mL} / \mathrm{min}$. Crotonic acid (6

$118 \mathrm{mM}$ ) was used as an internal standard.

120 RNA isolation and quality control

121 Frozen mycelium $(\approx 100 \mathrm{mg})$ of $R$. delemar ATCC 20344 was submerged in $1 \mathrm{~mL}$ of Trizol

122 reagent in a $2 \mathrm{~mL}$ tube, prefilled with a mix of glass beads with the following diameters: $1 \mathrm{~mm}$

$123(0.25 \mathrm{~g}), 0.1 \mathrm{~mm}(0.37 \mathrm{~g}), 5 \mathrm{~mm}$ (1 bead). Mycelium samples were disrupted using a FastPrep-24

124 Instrument (MP). After disruption, $200 \mu \mathrm{L}$ of chloroform were added and the mix was

125 homogenated for 10 seconds. The mix was poured into phase-lock gel tubes $(2 \mathrm{~mL})$, and

126 centrifuged at maximum speed in a table-top centrifuge. The RNA present in the water phase

127 was purified using the RNeasy Mini Kit (Qiagen), following the manufacturer's instructions. 
128 RNA integrity was assessed with an Experion system (Bio-Rad), and only high quality samples

129 (RIN value $\geq 8$ ) were selected for whole transcriptome shotgun sequencing.

130

\section{RNA sequencing and quality check}

132 Illumina RNA sequencing (RNA seq) using the Casava pipeline version 1.8.2 and subsequent

133 quality analysis of the FASTQ sequence reads was performed by BaseClear (Leiden, the

134 Netherlands). The number of reads obtained was 20'539'199 for the aerobic and 24'519'028 for

135 the anaerobic condition, with an average quality score (Phred) of 37.59 and 37.91, respectively.

136 The raw data has been submitted to the European Nucleotide Archive (ENA), and can be found

137 under the accession number PRJEB14210 (http://www.ebi.ac.uk/ena/data/view/PRJEB14210).

\section{RNA seq data processing}

140 Following the wokflow suggested and validated by Davids et al. [31], the RNA seq reads were

141 filtered using SortMeRNA v1.9 [32], cutadapt v1.2.1 [33] and PRINSEQ v0.20.2 [34]. De novo

142 assembly of the reads that passed the quality filtering was performed using the IDBA-UD

143 assembler v1.1 [35]. Read mapping and transcript coverage calculations were performed using

144 Bowtie2 v 2.2.2 [36] and BEDTools [37]. Note that in contrast to the proteomics analysis, which

145 was performed on both biological replicates, only one biological replicate per condition was sent

146 for RNA sequencing. The average nucleotide coverage is thus an indication of the transcript

147 levels of a given transcript the time of sampling, not the average of two biological replicates. A

148 more extensive description of the RNA seq data processing, including example commands for

149 every tool used, is given in File S1. 
151 Preparation of cell free extracts for proteomic analysis

152 R. delemar ATCC 20344 mycelium samples (2-3 g, press-dried), were washed with an ice-cold

$15320 \mathrm{mM}$ HEPES buffer $\mathrm{pH} 7.6$, containing $150 \mathrm{mM} \mathrm{NaCl}$, and resuspended in the same solution

154 containing 1\% (v/v) protease inhibitor cocktail for yeast and fungi (Sigma). Mycelium

155 suspensions were immediately disrupted using a French press (8000 psi). Cell free extracts were

156 centrifuged for $5 \mathrm{~min}$ at low speed (500 g), in order to remove unbroken cells and pellet debris.

157 The remaining supernantants were further processed for LC-MS/MS analysis.

158

159 Sample preparation for LC-MS/MS

160 The protein content of the $R$. delemar ATCC 20344 cell free extracts was determined using the

161 BCA protein assay (Thermo Fisher). Membrane-bound proteins were solubilised by mixing

162 volumes of each sample, containing $25 \mu \mathrm{g}$ of protein, with equal volumes of a $2 x$ solution of 20

163 mM HEPES pH 7.6, containing 1 M 6-aminocaproic acid and $10 \mathrm{~g} \mathrm{~L}^{-1}$ of n-dodecyl-beta-D-

164 maltoside. Cell free extract-detergent mixes were incubated in a thermoblock for $1 \mathrm{~h}$ at $20^{\circ} \mathrm{C}$ and

165 vigorous stirring (1000 rpm). Afterwards, samples were sonicated in a water bath for $15 \mathrm{~min}$, and

166 finally they were centrifuged at $22000 \mathrm{~g}$, in a benchtop centrifuge, for $30 \mathrm{~min}$. Obtained

167 supernatants were subsequently concentrated using MMicrocon YM-10 columns (cutoff, 10 kDa;

168 Millipore, Eschborn, Germany).

169

170 Samples from each biological replicate and culture condition were loaded into a 12\% SDS-

171 polyacrylamide gel, which was run until the loaded samples entered the gel. The gel was stained

172 according to the manufacturer's instructions using Page Blue staining (Fermentas) and rinsed

173 with ultrapure water. Each sample-gel lane was cut into one slice (approx. $1 \mathrm{~cm}^{2}$ ), carefully

174 sliced into smaller pieces of about $1 \mathrm{~mm}^{3}$ and transferred into microcentrifuge tubes. Samples 
175 were destained and equilibrated through three washing steps using the following solutions: 50

$176 \mathrm{mM}$ ammonium bicarbonate $(\mathrm{ABC})$ (incubated $5 \mathrm{~min}$ ), $\mathrm{ABC} /$ acetonitrile $(1: 1, \mathrm{v} / \mathrm{v})$ (incubated 5

$177 \mathrm{~min}$ ) and neat acetonitrile (incubated $5 \mathrm{~min}$ ). These washing steps were repeated two times. The

178 gel samples were then swelled in $10 \mathrm{mM}$ dithiothreitol (DTT) for $20 \mathrm{~min}$ at $56^{\circ} \mathrm{C}$ to reduce

179 protein disulfide bonds. Subsequently, the DTT solutions were removed and samples were

180 alkylated with $50 \mathrm{mM}$ 2-chloroacetamide in $\mathrm{ABC}$, for $20 \mathrm{~min}$, at room temperature, in the dark.

181 The 2-chloroacetamide solutions were removed, and samples were again washed twice with: neat

182 acetonitrile (incubated $5 \mathrm{~min}$ ), $\mathrm{ABC}$ (incubated $5 \mathrm{~min}$ ) and neat acetonitrile (incubated $5 \mathrm{~min}$ ).

183 Approximately $150 \mu \mathrm{L}$ of digestion buffer, containing sequencing grade modified trypsin (12.5

$184 \mathrm{ng} / \mu \mathrm{L}$ ) (Promega) in $\mathrm{ABC}$, was added to each sample, making sure that all gel pieces were kept

185 wet during digestion (adding, if necessary, additional $\mathrm{ABC}$ solution). Protein samples were

186 digested overnight at $37^{\circ} \mathrm{C}$. Peptide digestion products were extracted by adding $50 \mu \mathrm{L}$ of $2 \%$

187 trifluoroacetic acid (TFA), followed by an incubation step in a thermoblock for $20 \mathrm{~min}$, at room

188 temperature and vigorous stirring (1400 rpm). Gel pieces were then subjected to $20 \mathrm{~s}$ sonication

189 in a water bath, centrifuged and supernatants were transferred to new tubes. The peptide

190 extraction step was then repeated once by washing the gel pieces with buffer B ( $80 \%$ acetonitrile,

$1910.1 \%$ formic acid) followed by the mentioned incubation and sonication steps. Supernatants from

192 both extractions were pooled and samples were placed in a vacuum centrifuge for acetonitrile

193 evaporation util $20-40 \mu \mathrm{L}$ were left. Finally, samples were acidified by addition of TFA (1:1,

$194 \mathrm{v} / \mathrm{v}$ ) and peptide clean-up procedure, prior to LC-MS/MS analysis, was performed using the

195 "STop And Go Extraction" procedure as described before [38].

196 
197 Mass spectrometric measurements and proteomic data analysis

198 LC-MS/MS analysis was performed at the Radboud Proteomics Centre as described previously

199 [39]. Measurements were performed by nanoflow reversed-phase C18 liquid chromatography

200 (EASY nLC, Thermo Scientific) coupled online to a 7 Tesla linear ion trap Fourier-Transform

201 ion cyclotron resonance mass spectrometer (LTQ FT Ultra, Thermo Scientific). The LC-MS/MS

202 spectra obtained were identified and quantified using the maxQuant software [40]. The peptides

203 were mapped against the in silico proteomes of $R$. delemar ATCC 20344 (obtained from the

204 transcriptomics experiment) and RA 99-880 (obtained from Genbank, Project ID: 13066 [13])

205 with the default settings, described in [41]. Only proteins with 2 or more unique peptide hits

206 were considered for further analysis. The mass spectrometry proteomics data have been

207 deposited to the ProteomeXchange Consortium via the PRIDE [42] partner repository with the 208 dataset identifier PXD004600.

210 Metabolic pathway enrichment analysis

211 Metabolic enzymes were annotated using PRIAM [43], and subsequently assigned to KEGG

$212[44,45]$ pathways (see File S1 for details on the KEGG pathway mapping). Enrichment analysis

213 of differentially expressed pathways was performed using the hypergeometric test

214 implementation ("phyper") of the R software environment [46]. We used the identified proteins

215 that could be mapped to a KEGG pathway as the universe (with size $\mathrm{N}=277$ ). Note that the

216 terms "differentially expressed" and "overexpressed" refer to differences in relative protein

217 abundances, and denote a fold-change of 1.5 and 2 as lenient and stringent thresholds. 


\section{Results and Discussion}

220 Fumarate and ethanol production of ATCC 20344 grown under aerobic and anaerobic 221 conditions

222 We chose to work with R. delemar ATCC 20344, henceforth referred to as ATCC 20344, for its

223 ability to produce fumarate in high quantities [47]. ATCC 20344 was grown in batch

224 fermentations under nitrogen starved conditions. The fumarate production rate was controlled by 225 either supplying filtered air to the culture medium (aerobic condition), or restricting the amount 226 of oxygen by flushing the system with $\mathrm{N}_{2}$ (anaerobic condition). D-glucose, fumarate and

227 ethanol concentrations in the supernatant were measured via High Performance Liquid

228 Chromatography (HPLC) to determine the time point with the largest difference in fumarate

229 yield. The HPLC analysis showed comparable D-glucose consumption rates in the two

230 conditions (Fig. 2), with an average of $0.15 \pm 0.03 \mathrm{~g} / \mathrm{h}$ and $0.11 \pm 0.03 \mathrm{~g} / \mathrm{h}$ for the aerobic and

231 anaerobic condition, respectively. Fumarate production was higher in the aerobic condition,

232 whereas in the anaerobic condition ethanol production prevailed. Note that Lin et al. showed that

233 Rhizopus spp. grow very poorly under absolute anaerobic conditions, but that most of the tested

234 strains grew "quite well" under microaerobic conditions [48]. The use of silicone tubing on our

235 fermentors, which are slightly oxygen permeable even when flushed with pure nitrogen gas [49],

236 allowed ATCC 20344 to utilise glucose at the same rate as under aerobic conditions, while

237 keeping fumarate production to a minimum. However, the amount of oxygen entering through

238 the silicone tubing was below the detection limit of the probes measuring dissolved oxygen in

239 the fermentors, and we refer to the two conditions as "aerobic" and "anaerobic" rather than

240 "aerobic" and "microaerobic". 


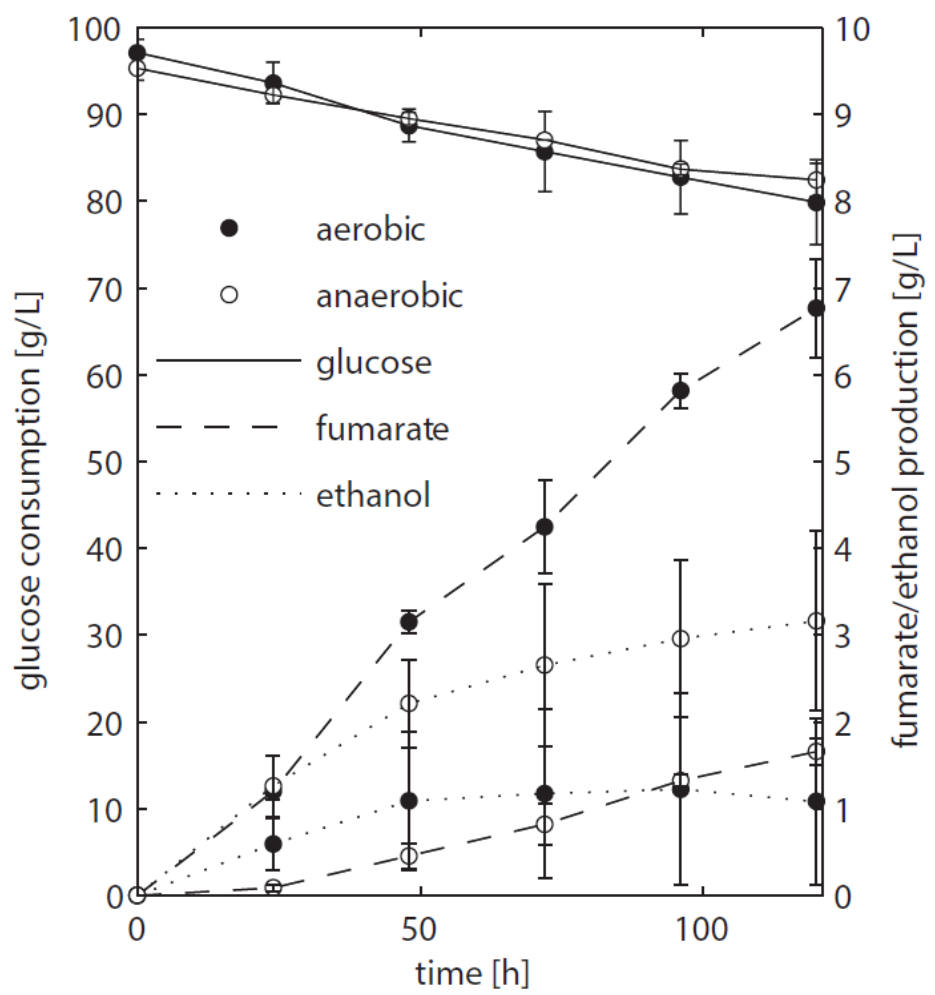

Figure 2. HPLC analysis of fermentation broth of $R$. delemar ATCC 20344 grown under aerobic and anaerobic conditions.

245 Total D-glucose consumption and fumarate and ethanol production of $R$. delemar ATCC 20344.

246 The measurement points show the average of two biological replicates.

248 The fumarate yields (gram per gram substrate D-glucose consumed) are summarised in Table 1.

249 The maximum fumarate yield $(0.41 \pm 0.06 \mathrm{~g} / \mathrm{g})$ in the aerobic condition was observed after 96

250 hours of fermentation. A comparable yield $(0.35 \pm 0.05 \mathrm{~g} / \mathrm{g})$ was already observed after 24 hours

251 of fermentation. In contrast, the fumarate yield in the anaerobic condition increased continuously

252 at a slow pace, being highest after 120 hours of fermentation $(0.13 \pm 0.02 \mathrm{~g} / \mathrm{g})$. Thus, the largest

253 difference in fumarate yield between the two conditions was observed at the start of the

254 experiment, and we chose $\mathrm{t}=24 \mathrm{~h}$ as the time point for the transcriptome and proteome analyses. 
256 Table 1. Fumarate yields of ATCC 20344 grown under aerobic and anaerobic conditions.

\begin{tabular}{|l|l|l|}
\hline \multirow{2}{*}{ Time $[\mathrm{h}]$} & \multicolumn{2}{|l|}{ Fumarate yield $\pm \mathrm{sd}[\mathrm{g} / \mathrm{g}$ D-glucose $]$} \\
\cline { 2 - 3 } & aerobic & anaerobic \\
\hline 24 & $0.349 \pm 0.055$ & $0.029 \pm 0.015$ \\
\hline 48 & $0.375 \pm 0.001$ & $0.077 \pm 0.015$ \\
\hline 72 & $0.380 \pm 0.055$ & $0.098 \pm 0.012$ \\
\hline 96 & $0.411 \pm 0.063$ & $0.115 \pm 0.014$ \\
\hline 120 & $0.397 \pm 0.044$ & $0.132 \pm 0.022$ \\
\hline
\end{tabular}

257

Transcriptome and proteome of ATCC 20344 under high and low fumarate producing conditions

Enzyme activities, and thus metabolism, are affected by various factors such as post-translational

modifications, allosteric control, and substrate availability. Metabolic fluxes can therefore not be inferred directly from protein abundances. Nevertheless, contrasting enzyme abundance levels between the high and low fumarate producing condition (ATCC 20344 snapshot proteomes) indicate differences in the metabolic state of ATCC 20344 at the time point of sampling. To determine differential protein abundances via LC-MS/MS, a reference proteome database is required for peptide mass fingerprinting. To date, $R$. delemar RA 99-880, henceforth referred to as RA 99-880, is the only fully sequenced $R$. delemar strain of which also the proteome is publicly available [13]. However, if the RA 99-880 reference proteome is used as only reference database, conservative amino acid substitutions in ATCC 20344 will reduce the sensitivity, as protein identification relies on an exact peptide mass. To provide a complete database of the metabolic potential as well as an overview of the metabolic state of ATCC 20344 under high and

272 low fumarate producing conditions, we combined transcriptomic and proteomic data of ATCC 
27320344 grown under high and low fumarate producing conditions. The transcriptome was used to 274 construct a database of the ATCC 20344 in silico proteome, and the relative protein abundances

275 were obtained by mapping the peptides from the snapshot proteomes against both the ATCC

27620344 and RA 99-880 in silico proteomes, the latter to account for possible errors in the de novo

277 transcript assembly. The experimental setup is outlined in Fig. 3.

278

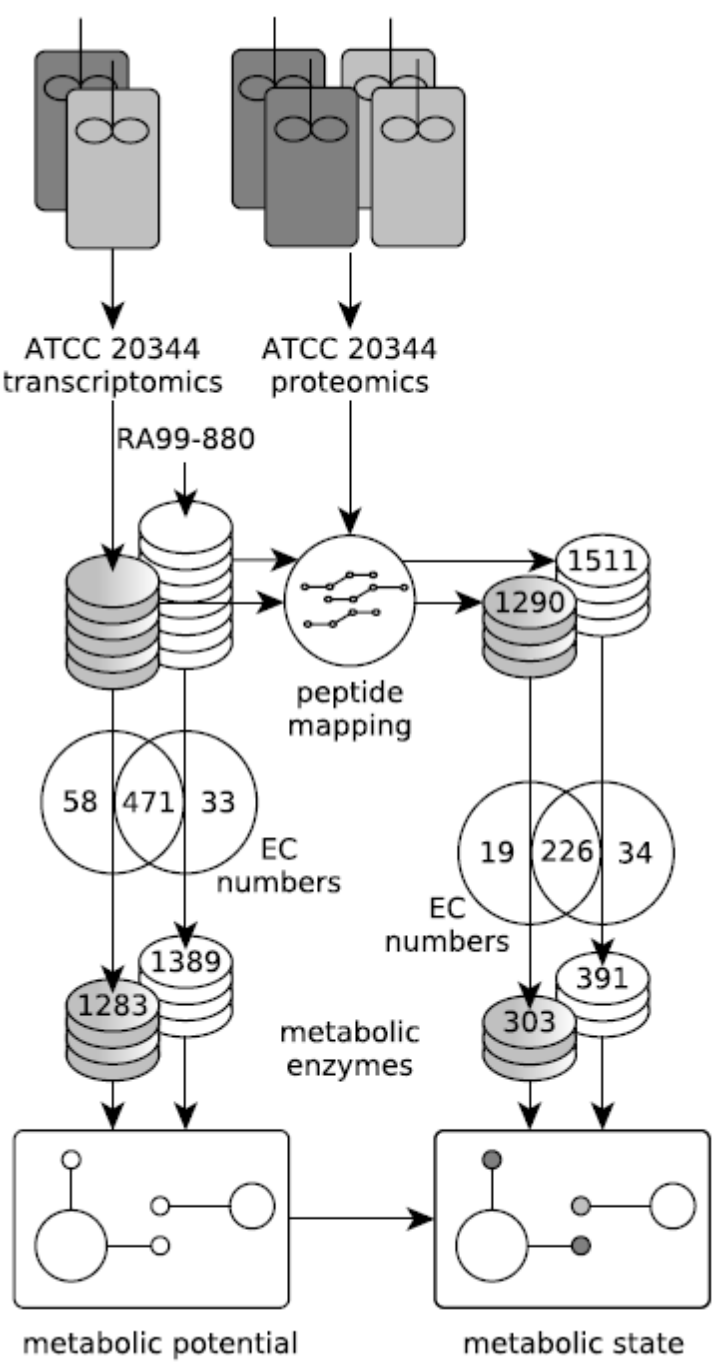

\section{Figure 3. Experimental setup.}

281 Workflow to establish the metabolic potential and metabolic state of ATCC 20344 grown under

282 high and low fumarate producing conditions. The metabolic enzymes predicted in the ATCC 
28320344 and RA 99-880 in silico proteomes provide a map of the metabolic potential, while the

284 metabolic enzymes identified in the proteomics experiment were used to determine the metabolic

285 state of ATCC 20344 under high and low fumarate producing conditions.

286

287 The RNA seq reads obtained from the aerobic and anaerobic conditions were combined into one 288 dataset, and assembled de novo, resulting in 13'531 contigs (File S2). We used PRIAM [43] to 289 assign EC numbers to the six-frame translation products of the de novo contigs, as well as to the

290 RA 99-880 reference proteome (File S3). In ATCC 20344, we predicted 1283 metabolic

291 enzymes, covering 529 EC numbers. In RA 99-880, we predicted 1389 metabolic enzymes,

292 covering 504 EC numbers. The metabolic enzymes were mapped to KEGG pathway maps

$293[44,45]$ in order to obtain a rough estimate of the metabolic potential of $R$. delemar.

295 The proteins obtained from the aerobic and anaerobic conditions were subjected to a shotgun 296 proteomics analysis. A total of 1290 and 1511 proteins were identified in the ATCC 20344 and

297 RA 99-880 proteomes, respectively. Roughly one third of the identified proteins comprised 298 metabolic enzymes. A list of all EC numbers predicted in the ATCC 20344 and RA 99-880 in

299 silico proteomes, as well as the relative protein abundances and average nucleotide coverages of

300 the proteins and transcripts identified in the experimental conditions (resulting in a total of 1970

301 proteins, although some are duplicates due to combining ATCC 20344 and RA 99-880 in one

302 file), can be found in Table S4. The protein pathway coverage (number of ECs per pathway

303 covered by proteins with the predicted function in ATCC 20344 and RA 99-880) is given in 304 Table S5. 
306 Metabolic pathway enrichment analysis

307 To determine which pathways play an important role in fumarate accumulation in ATCC 20344,

308 we obtained a list of enzymatic proteins that directly consume or produce fumarate according to

309 the KEGG database [44,45], and analysed their presence and abundance in the ATCC 20344

310 high and low fumarate producing conditions (Table 2). In addition, we performed pathway

311 enrichment analysis of differentially expressed enzymes (Table 3, Table S5).

312 Table 2. List of enzymes involved in fumarate metabolism with their respective protein 313 abundances under high and low fumarate producing conditions.

\begin{tabular}{|c|c|c|c|c|c|}
\hline \multirow[t]{2}{*}{ EC number } & \multirow[t]{2}{*}{$\begin{array}{l}\text { Consensus protein } \\
\text { identifier }^{\mathrm{a}}\end{array}$} & \multicolumn{2}{|c|}{$\begin{array}{l}\text { Relative protein abundance } \pm \mathrm{sd} \\
{[\%]}\end{array}$} & \multirow[t]{2}{*}{$\begin{array}{l}\log _{2} \mathrm{FC} \\
\text { aerobic/anaerobic }\end{array}$} & \multirow[t]{2}{*}{ Enzyme name } \\
\hline & & aerobic & anaerobic & & \\
\hline 4.2 .1 .2 & Rd_01690 & $1.51 \pm 0.16$ & $0.66 \pm 0.06$ & 1.21 & $\begin{array}{l}\text { fumarate } \\
\text { hydratase (fumarase, FumR) }\end{array}$ \\
\hline 4.3 .2 .1 & Rd_00962 & $0.09 \pm 0.01$ & $0.06 \pm 0.02$ & 0.60 & argininosuccinate lyase (ASL) \\
\hline 1.3 .98 .1 & Rd_00873 & $0.04 \pm 4 \mathrm{e}-3$ & $0.01 \pm 2 \mathrm{e}-3$ & 1.34 & dihydroorotate dehydrogenase \\
\hline 3.7 .1 .2 & Rd_01207 & $0.03 \pm 3 e-3$ & 0.00 & - & fumarylacetoacetase \\
\hline 1.3.5.1 & Rd_01783 & $0.01 \pm 2 \mathrm{e}-3$ & 0.00 & - & succinate dehydrogenase \\
\hline 4.3 .2 .2 & Rd_00964 & $5 e-3 \pm 7 e-4$ & $0.01 \pm 8 \mathrm{e}-7$ & -1.59 & adenylosuccinate lyase \\
\hline
\end{tabular}

314 aIdentifiers refer to IDs in Table S4. Note that, where possible, ATCC 20344 enzymes were

315 prioritised. In this case, all enzymes were identified in the ATCC 20344 proteome.

317 Table 3. Metabolic pathway enrichment analysis.

\begin{tabular}{|c|c|c|c|c|c|c|c|c|}
\hline \multirow[t]{2}{*}{ Pathway } & \multirow{2}{*}{$\begin{array}{l}\text { \# ECs in } \\
\text { reference } \\
\text { pathway }\end{array}$} & \multirow{2}{*}{$\begin{array}{l}\text { \# ECs } \\
\text { (proteins) } \\
\text { identified }\end{array}$} & \multicolumn{2}{|c|}{$\begin{array}{l}\text { Differentially } \\
\text { expressed }\end{array}$} & \multicolumn{4}{|c|}{ Overexpressed (aerobic) } \\
\hline & & & $\begin{array}{l}\text { \# proteins } \\
\text { (1.5-fold) }\end{array}$ & p-value & $\begin{array}{l}\text { \# proteins } \\
\text { (1.5-fold) }\end{array}$ & p-value & $\begin{array}{l}\text { \# proteins } \\
\text { (2-fold) }\end{array}$ & p-value \\
\hline
\end{tabular}




\begin{tabular}{|c|c|c|c|c|c|c|c|c|}
\hline $\begin{array}{l}\text { Alanine, aspartate } \\
\text { and glutamate } \\
\text { metabolism }\end{array}$ & 50 & $12(16)$ & 15 & 0.040 & 10 & 0.102 & 7 & 0.264 \\
\hline $\begin{array}{l}\text { Arginine } \\
\text { biosynthesis }\end{array}$ & 32 & 12 (14) & 13 & 0.070 & 10 & 0.033 & 5 & 0.534 \\
\hline $\begin{array}{l}\text { beta-Alanine } \\
\text { metabolism }\end{array}$ & 37 & $8(11)$ & 9 & 0.389 & 9 & 0.011 & 9 & 0.001 \\
\hline $\begin{array}{l}\text { Citrate cycle } \\
\text { (TCA cycle) }\end{array}$ & 25 & 15 (19) & 14 & 0.589 & 10 & 0.292 & 9 & 0.143 \\
\hline $\begin{array}{l}\text { Glycolysis / } \\
\text { Gluconeogenesis }\end{array}$ & 49 & $19(31)$ & 19 & 0.957 & 10 & 0.946 & 9 & 0.777 \\
\hline $\begin{array}{l}\text { Oxidative } \\
\text { phosphorylation }\end{array}$ & 11 & $8(20)$ & 16 & 0.327 & 14 & 0.014 & 9 & 0.189 \\
\hline $\begin{array}{l}\text { Pyrimidine } \\
\text { metabolism }\end{array}$ & 65 & $11(13)$ & 11 & 0.267 & 9 & 0.056 & 6 & 0.243 \\
\hline $\begin{array}{l}\text { Pyruvate } \\
\text { metabolism }\end{array}$ & 68 & $15(23)$ & 17 & 0.565 & 11 & 0.433 & 11 & 0.102 \\
\hline $\begin{array}{l}\text { Valine, leucine } \\
\text { and isoleucine } \\
\text { degradation }\end{array}$ & 38 & 10 (14) & 11 & 0.446 & 8 & 0.230 & 8 & 0.055 \\
\hline
\end{tabular}

318

319 We found that, amongst the enzymes which interact directly with fumarate and were identified in

320 the ATCC 20344 snapshot proteomes, FumR (EC 4.2.1.2), is the most highly abundant enzyme,

321 both under high and low fumarate producing conditions (Table 2). Although there is no clear

322 enrichment of the TCA cycle enzymes among the differentially expressed metabolic proteins

323 (Table 3), the three enzymes of the reductive TCA cycle, PYC (EC 6.4.1.1, relative protein

324 abundance $\left[\%\right.$ a.u.]: aerobic $=2.14 \pm 0.31$, anaerobic $=0.40 \pm 0.02, \log _{2} \mathrm{FC}($ aerobic/anaerobic $)=$ 
325 2.44), $\mathrm{MDH}$ (3 isozymes with EC 1.1.1.37, relative protein abundance [\% a.u.]: aerobic $=0.48 \pm$

$3260.06 / 0.15 \pm 0.06 / 2.43 \pm 0.08$, anaerobic $=0.10 \pm 0.01 / 0.02 \pm 0.00 / 1.85 \pm 0.09$,

$327 \log _{2} \mathrm{FC}($ aerobic/anaerobic $\left.)=2.20 / 3.19 / 0.40\right)$, and FumR $(\mathrm{EC} 4.2 .1 .2$, see Table 2 for relative

328 protein abundance), are all overexpressed in the high fumarate producing condition .

330 The second most highly abundant protein related to fumarate metabolism is argininosuccinate

331 lyase (ASL) (EC 4.3.2.1). ASL is a urea cycle enzyme involved in arginine biosynthesis. The

332 arginine biosynthesis pathway showed a significant number of differentially expressed proteins

333 (Table 3), and we found that the enzymes comprising the urea cycle are overexpressed in the

334 high fumarate producing condition (Table 4). This suggests that in ATCC 20344, the urea cycle

335 plays an important role in fumarate accumulation. Most interestingly, ASL and FUM constitute a

336 crucial link between carbon and nitrogen metabolism by connecting the TCA- and urea cycles

337 (also referred to as "Krebs bicycle").

338

Table 4. Urea cycle enzymes with their respective protein abundances under high and 340 low fumarate producing conditions.

\begin{tabular}{|c|c|c|c|c|c|}
\hline \multirow[t]{2}{*}{$\begin{array}{l}\text { EC } \\
\text { number }\end{array}$} & \multirow[t]{2}{*}{$\begin{array}{l}\text { Consensus } \\
\text { protein } \\
\text { identifier (ref) }\end{array}$} & \multicolumn{2}{|c|}{$\begin{array}{l}\text { Relative protein } \\
\text { abundance } \pm \text { sd } \\
{[\%]}\end{array}$} & \multirow[t]{2}{*}{$\begin{array}{l}\log _{2} \mathrm{FC} \\
\text { aerobic/anaerobic }\end{array}$} & \multirow[t]{2}{*}{ Enzyme name } \\
\hline & & aerobic & anaerobic & & \\
\hline 2.1 .3 .3 & Rd_01058 (A) & $\begin{array}{l}0.03 \pm \\
0.01\end{array}$ & $\begin{array}{l}0.02 \pm \\
8 \mathrm{e}-3\end{array}$ & 0.51 & $\begin{array}{l}\text { ornithine } \\
\text { carbamoyltransferase (OTC) }\end{array}$ \\
\hline 6.3 .4 .5 & Rd_01708 (R) & $\begin{array}{l}0.86 \pm \\
0.07\end{array}$ & $\begin{array}{l}0.57 \pm \\
0.05\end{array}$ & 0.59 & $\begin{array}{l}\text { argininosuccinate synthase } \\
\text { (ASS) }\end{array}$ \\
\hline 6.3 .4 .5 & Rd_01709 (R) & 0.00 & $0.04 \pm$ & - & argininosuccinate synthase \\
\hline
\end{tabular}




\begin{tabular}{|l|l|l|l|l|l|}
\hline & & & 0.02 & & (ASS) \\
\hline 4.3.2.1 & Rd_00962 (A) & $0.09 \pm$ & $0.06 \pm$ & & argininosuccinate lyase (ASL) \\
& & 0.01 & 0.02 & 0.60 & \\
\hline 3.5.3.1 & Rd_00988 (R) & $0.13 \pm$ & $0.07 \pm$ & & arginase (ARG) \\
& & 0.02 & 0.01 & 0.97 & \\
\hline 3.5.3.1 & Rd_00989 (R) & $0.19 \pm$ & $0.11 \pm$ & & arginase (ARG) \\
& & 0.02 & 0.03 & 0.76 & \\
\hline
\end{tabular}

adentifiers refer to IDs in Table S4. Note that, where possible, ATCC 20344 enzymes were

342 prioritised. Letters in brackets refer to the reference proteome, with $\mathrm{A}=\mathrm{ATCC} 20344$ and $\mathrm{R}=$

343 RA 99-880.

344

345 The observed protein abundances for FumR and ASL offer an explanation for the importance of

346 a high carbon:nitrogen ratio for fumarate accumulation in Rhizopus spp [2,3]. In humans,

347 starvation induces a net breakdown of stored energy sources, starting with fatty acids and, when

348 exposed to prolonged starving conditions, proteins from muscle tissue [50]. The degradation of

349 protein, or amino acids, results in the liberation of ammonia, which is then carried to the urea

350 cycle as L-glutamate [51]. In the urea cycle, the L-glutamate is converted to urea, which is

351 subsequently excreted [51]. Based on the significant enrichment scores of pathways involved in

352 amino acid metabolism (Table 3), we propose that the nitrogen starvation, induced by the

353 transfer of ATCC 20344 from growth- to production medium, triggers a similar switch in

354 metabolism, and amino acid catabolism starts to occur. The resulting fluxes through the urea

355 cycle yield an excess of fumarate (Fig. 4). 


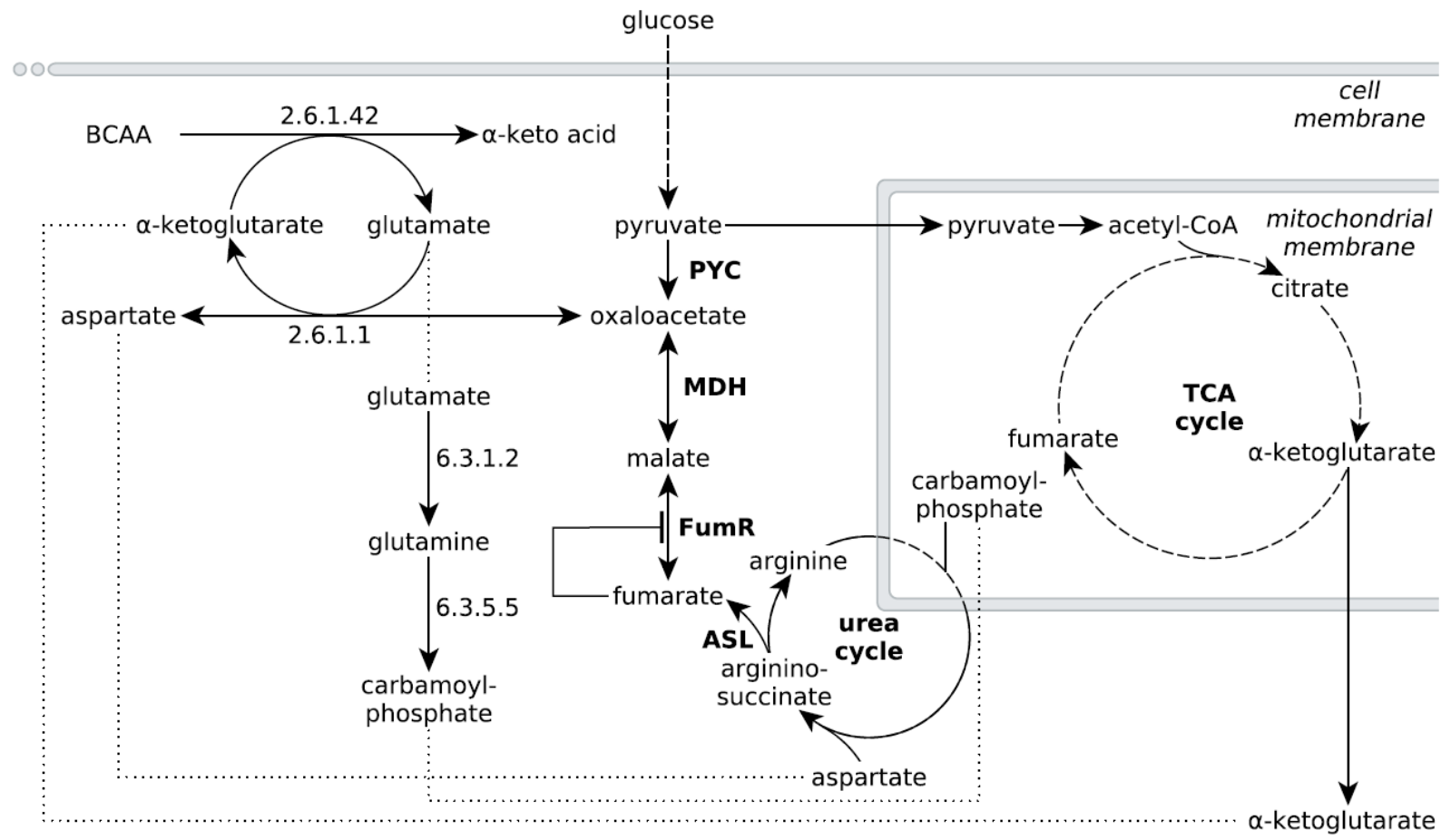

Figure 4. Extended network of metabolic pathways involved in fumarate metabolism in $R$.

360 The extended model of fumarate accumulation reconstructed from the ATCC 20344 snapshot

361 proteomes under high and low fumarate producing conditions takes the formation of fumarate

362 via the urea cycle into account.

363

364 Specifically, the pathway for the degradation of the branched-chain amino acids (BCAA) valine,

365 leucine and isoleucine shows a significant number of overexpressed enzymes in the high

366 fumarate producing condition. BCAA catabolism is initiated by BCAA aminotransferase (EC

367 2.6.1.42), which catalyses the transfer of an amino group from any of the three BCAAs to $\alpha$ -

368 ketoglutarate, yielding L-glutamate and the respective $\alpha$-keto acid as products (Fig. 4). Under

369 starvation conditions in which both the nitrogen and carbon source in the culture medium are

370 limited, the carbon skeletons of the deaminated amino acids can be used to replenish acetyl-CoA

371 (from leucine), or the TCA cycle intermediate succinyl-CoA (from valine) or both of these 
372 metabolites (from isoleucine), and thereby, ultimately, to generate energy for growth. Under

373 conditions of excess carbon and limited nitrogen, however, it is unlikely that amino acid

374 catabolism is driven by energy demand of the organism. More importantly, it is crucial for $R$.

375 delemar grown under nitrogen depleted conditions to decouple carbon catabolism from cell

376 proliferation, as there is little nitrogen available for de novo protein biosynthesis.

377

378 One way to decouple carbon catabolism from biomass formation is by reducing the amount of

379 ATP generated. Under aerobic growth conditions, ATP is generated via oxidative

380 phosphorylation. Under anaerobic conditions, R. delemar generates ATP via ethanol

381 fermentation (Fig. 1). Another option for ATP generation is alternative respiration, mediated by

382 the key enzyme alternative oxidase (AOX). AOX diverts the electrons passing through the

383 electron transport chain in the mitochondria at the ubiquinone pool and transfers them directly to

384 oxygen, thereby bypassing the oxidative phosphorylation complexes III and IV, resulting in an

385 overall lower ATP yield. Gu et al. found that the activity of AOX is positively correlated with

386 fumarate production in R. delemar [52]. In contrast, we identified AOX (Rd_00967 (A)) only in

387 the snapshot proteome of the anaerobic condition. The transcriptomics measurements further

388 underpin our proteomics results, since aox was overexpressed ( $>4$-fold) in the anaerobic

389 condition (Table S4). This might seem counterintuitive at first, since the expression of aox is

390 generally regarded as a means of dealing with increased oxidative stress. However, the electron

391 flow through AOX has been found to be inversely proportional to nitrogen availability in various

392 different plant systems [53]. The increase of AOX under nitrogen limited conditions and the

393 resulting decrease of the respiratory ATP yield have been associated with a deliberately reduced 
394 efficiency in converting carbon to biomass; by using the non-energy conserving AOX, the

395 "redundant" carbohydrate can be metabolised without being coupled to growth.

396

397 Another way of decoupling carbon catabolism from energy generation, and thereby cell

398 proliferation, is channelling the products from amino acid degradation to the mitochondria for

399 mitochondrial protein synthesis, and thereby away from cytosolic protein synthesis; a mechanism

400 suggested to take place under nitrogen starvation conditions in human cells, irrespective of the

401 D-glucose availability [54]. In this, amino acid catabolism is the first step to adapt to nitrogen

402 limiting conditions, and we propose that, in a similar mechanism, the urea cycle plays a key role

403 for the accumulation of fumarate in R. delemar. This is supported by the work of Chen et al.,

404 who showed that, from a range of selected enzymes, overexpressing ASL, while keeping the

405 expression of adenylosuccinate lyase low, resulted in the highest fumarate titer in Torulopsis

406 glabrata [14].

407

\section{Conclusions}

409 The accumulation of fumarate in the natural fumarate producer $R$. delemar has been mostly

410 attributed to the consecutive conversion of pyruvate to oxaloacetate, L-malate and fumarate by

411 cytosolic enzymes of the reductive TCA cycle. In addition, our proteomics data have revealed

412 that the nitrogen-limitation under fumarate producing conditions induces amino acid catabolism,

413 which leads to an increased flux through the urea cycle. Further investigation is required to

414 verify the involvement of the urea cycle in $R$. delemar fumarate accumulation. As $R$. delemar can

415 utilise urea as nitrogen source, higher fluxes through the urea cycle will not necessarily lead to a

416 measurable increase of urea in the medium. Our comparative proteomics analysis of high and 
417 low fumarate producing conditions in R. delemar ATCC 20344 has resulted in a novel holistic

418 view on fumarate production that expands the knowledge on fumarate production in this fungus,

419 and provides a basis for further biochemical explorations regarding biotechnological fumarate

420 production.

421

422

Acknowledgements

423

We would like to thank Sybe Hartmans, Michael Volpers and Brendan Ryback for critically

424

reading and commenting on draft versions of the manuscript. In addition, we would like to thank

425

Bastian Hornung for valuable input for the RNA seq data analysis, Ruud Weusthuis for valuable

426

feedback on general aspects of this manuscript, and Tom Schonewille and Merlijn van Gaal for

427

their contribution in the experimental part of this work.

428

429

430

431

432

433

434

435

436

437

438

439

440

441

442

443

444

445

446

447

448

449

450

\section{References}

1. Foster JW, Waksman SA. The Production of Fumaric Acid by Molds Belonging to the Genus Rhizopus. J Am Chem Soc. American Chemical Society; 1939;61: 127-135. doi:10.1021/ja01870a043

2. Magnuson J, Lasure L. Organic acid production by filamentous fungi. Adv fungal Biotechnol Ind Agric Med. 2004; 307-340. Available: http://link.springer.com/chapter/10.1007/978-1-4419-8859-1_12

3. Goldberg I, Rokem JS, Pines O. Organic acids: old metabolites, new themes. J Chem Technol Biotechnol. 2006;81: 1601-1611. doi:10.1002/jctb.1590

4. Rhodes R a, Moyer a J, Smith ML, Kelley SE. Production of fumaric acid by Rhizopus arrhizus. Appl Microbiol. 1959;7: 74-80. Available:

http://www.pubmedcentral.nih.gov/articlerender.fcgi?artid=1057471\&tool=pmcentrez\&re ndertype $=$ abstract

5. Z.Y. Zhang, B. Jin JMK. Production of lactic acid and byproducts from waste potato starch by Rhizopus arrhizus : role of nitrogen sources. World J Microbiol Biotechnol. 2007;23: 229-236.

6. J. W. Foster, S.F. Carson, D.S Anthony, J.B. Davis, W.E. Jefferson MVL. AEROBIC FORMATION OF FUMARIC ACID IN THE MOLD RHIZOPUS NIGRICANS:

SYNTHESIS BY DIRECT C2 CONDENSATION. Proc Natl Acad Sci. 1949;35.

7. Wright BE, Longacre a, Reimers J. Models of metabolism in Rhizopus oryzae. J Theor Biol. 1996;182: 453-7. doi:10.1006/jtbi.1996.0186

8. Straathof AJJ, van Gulik WM. Production of fumaric acid by fermentation. Subcell Biochem. 2012;64: 225-40. doi:10.1007/978-94-007-5055-5_11 
451 9. Roa Engel CA, Straathof AJJ, Zijlmans TW, van Gulik WM, van der Wielen LAM.

452

453

454

455

456

457

458

459

460

461

462

463

464

465

466

467

468

469

470

471

472

473

474

475

476

477

478

479

480

481

482

483

484

485

486

487

488

489

490

491

492

493

494

495

496
Fumaric acid production by fermentation. Appl Microbiol Biotechnol. 2008;78: 379-89. doi:10.1007/s00253-007-1341-x

10. Meussen BJ, de Graaff LH, Sanders JPM, Weusthuis R a. Metabolic engineering of Rhizopus oryzae for the production of platform chemicals. Appl Microbiol Biotechnol. 2012;94: 875-86. doi:10.1007/s00253-012-4033-0

11. Zhang B, Skory CD, Yang S-T. Metabolic engineering of Rhizopus oryzae: effects of overexpressing pyc and pepc genes on fumaric acid biosynthesis from glucose. Metab Eng. 2012;14: 512-20. doi:10.1016/j.ymben.2012.07.001

12. Zhang B, Yang S-T. Metabolic engineering of Rhizopus oryzae: Effects of overexpressing fumR gene on cell growth and fumaric acid biosynthesis from glucose. Process Biochem. 2012;47: 2159-2165. doi:10.1016/j.procbio.2012.08.009

13. Ibrahim AS, Skory C, Grabherr MG, Burger G, Butler M, Elias M, Idnurm A, Lang BF, Sone T, Abe A, Calvo SE, Corrochano LM, Engels R, Fu J, Hansberg W, Kim J-M, Kodira CD, Koehrsen MJ, Liu B, Miranda-Saavedra D, O'Leary S, Ortiz-Castellanos L, Poulter R, Rodriguez-Romero J, Ruiz-Herrera J, Shen Y-Q, Zeng Qiandong, Galagan J, Birren BW, Cuomo CA,Wickes BL. Genomic analysis of the basal lineage fungus Rhizopus oryzae reveals a whole-genome duplication. PLoS Genet. 2009;5: e1000549. doi:10.1371/journal.pgen.1000549

14. Chen X, Wu J, Song W, Zhang L, Wang H, Liu L. Fumaric acid production by Torulopsis glabrata: engineering the urea cycle and the purine nucleotide cycle. Biotechnol Bioeng. 2015;112: 156-67. doi:10.1002/bit.25334

15. Li N, Zhang B, Wang Z, Tang Y-J, Chen T, Zhao X. Engineering Escherichia coli for fumaric acid production from glycerol. Bioresour Technol. 2014;174: 81-7. doi:10.1016/j.biortech.2014.09.147

16. Song CW, Kim DI, Choi S, Jang JW, Lee SY. Metabolic engineering of Escherichia coli for the production of fumaric acid. Biotechnol Bioeng. 2013;110: 2025-34. doi:10.1002/bit.24868

17. Wei L, Liu J, Qi H, Wen J. Engineering Scheffersomyces stipitis for fumaric acid production from xylose. Bioresour Technol. 2015;187: 246-54.

doi:10.1016/j.biortech.2015.03.122

18. Xu G, Chen X, Liu L, Jiang L. Fumaric acid production in Saccharomyces cerevisiae by simultaneous use of oxidative and reductive routes. Bioresour Technol. 2013;148: 91-6. doi:10.1016/j.biortech.2013.08.115

19. Xu G, Liu L, Chen J. Reconstruction of cytosolic fumaric acid biosynthetic pathways in Saccharomyces cerevisiae. Microb Cell Fact. BioMed Central; 2012;11: 24. doi:10.1186/1475-2859-11-24

20. Xu G, Zou W, Chen X, Xu N, Liu L, Chen J. Fumaric acid production in Saccharomyces cerevisiae by in silico aided metabolic engineering. PLoS One. Public Library of Science; 2012;7: e52086. doi:10.1371/journal.pone.0052086

21. Zhang T, Wang Z, Deng L, Tan T, Wang F, Yan Y. Pull-in urea cycle for the production of fumaric acid in Escherichia coli. Appl Microbiol Biotechnol. 2015;99: 5033-44. doi:10.1007/s00253-015-6556-7

22. Chen X, Zhu P, Liu L. Modular optimization of multi-gene pathways for fumarate production. Metab Eng. 2016;33: 76-85. doi:10.1016/j.ymben.2015.07.007

23. Romano AH, Bright MM, Scott WE. Mechanism of fumaric acid accumulation in 
501

502

503

504

505

506

507

508

509

510

511

512

513

514

515

516

517

518

519

520

521

522

523

524

525

526

527

528

529

530

531

532

533

534

535

536

537

538

539

540

541

542

Rhizopus nigricans. J Bacteriol. 1967;93: 600-4. Available:

http://www.pubmedcentral.nih.gov/articlerender.fcgi?artid=276484\&tool=pmcentrez\&ren dertype $=$ abstract

24. Overman SA, Roman H. Pyruvate carboxylase of Rhizopus nigricans and its role in fumaric acid production. Biochem Biophys Res Commun. 1969;37: 457-463.

25. Osmani S a, Scrutton MC. The sub-cellular localisation and regulatory properties of pyruvate carboxylase from Rhizopus arrhizus. Eur J Biochem. 1985;147: 119-28. Available: http://www.ncbi.nlm.nih.gov/pubmed/3971971

26. Kenealy W, Zaady E, du Preez JC, Stieglitz B, Goldberg I. Biochemical Aspects of Fumaric Acid Accumulation by Rhizopus arrhizus. Appl Environ Microbiol. 1986;52: 128-33. Available:

http://www.pubmedcentral.nih.gov/articlerender.fcgi?artid=203406\&tool=pmcentrez\&ren dertype $=$ abstract

27. Peleg Y, Battat E, Scrutton M, Goldberg I. Isoenzyme pattern and subcellular localisation of enzymes involved in fumaric acid accumulation by Rhizopus oryzae. Appl Microbiol

Biotechnol. Springer-Verlag; 1989;32: 334-339. doi:10.1007/BF00184985

28. de Jongh WA, Nielsen J. Enhanced citrate production through gene insertion in Aspergillus niger. Metab Eng. 2008;10: 87-96. doi:10.1016/j.ymben.2007.11.002

29. Abe A, Oda Y, Asano K, Sone T. Rhizopus delemar is the proper name for Rhizopus oryzae fumaric-malic acid producers. Mycologia. 2007;99: 714-22. Available:

http://www.ncbi.nlm.nih.gov/pubmed/18268905

30. Abe A, Sone T, Sujaya IN, Saito K, Oda Y, Asano K, Tomita F. rDNA ITS sequence of Rhizopus oryzae: its application to classification and identification of lactic acid producers. Biosci Biotechnol Biochem. Japan Society for Bioscience, Biotechnology, and Agrochemistry; 2003;67: 1725-31. doi:10.1271/bbb.67.1725

31. Davids M, Hugenholtz F, Dos Santos VM, Smidt H, Kleerebezem M, Schaap PJ. Functional profiling of unfamiliar microbial communities using a validated de novo assembly metatranscriptome pipeline. Jordan IK, editor. PLoS One. Public Library of Science; 2016;11: e0146423. doi:10.1371/journal.pone.0146423

32. Kopylova E, Noé L, Touzet H. SortMeRNA: fast and accurate filtering of ribosomal RNAs in metatranscriptomic data. Bioinformatics. 2012;28: 3211-7. doi:10.1093/bioinformatics/bts611

33. Martin M. Cutadapt removes adapter sequences from high-throughput sequencing reads [Internet]. EMBnet.journal. 2011. pp. 10-12. Available: http://journal.embnet.org/index.php/embnetjournal/article/view/200/479

34. Schmieder R, Edwards R. Quality control and preprocessing of metagenomic datasets. Bioinformatics. 2011;27: 863-4. doi:10.1093/bioinformatics/btr026

35. Peng Y, Leung HCM, Yiu SM, Chin FYL. IDBA-UD: a de novo assembler for single-cell and metagenomic sequencing data with highly uneven depth. Bioinformatics. 2012;28: 1420-8. doi:10.1093/bioinformatics/bts174

36. Langmead B, Salzberg SL. Fast gapped-read alignment with Bowtie 2. Nat Methods. 2012;9: 357-9. doi:10.1038/nmeth.1923

37. Quinlan AR, Hall IM. BEDTools: a flexible suite of utilities for comparing genomic features. Bioinformatics. 2010;26: 841-2. doi:10.1093/bioinformatics/btq033

38. Rappsilber J, Ishihama Y, Mann M. Stop and Go Extraction Tips for Matrix-Assisted Laser Desorption/Ionization, Nanoelectrospray, and LC/MS Sample Pretreatment in 
543

544

545

546

547

548

549

550

551

552

553

554

555

556

557

558

559

560

561

562

563

564

565

566

567

568

569

570

571

572

573

574

575

576

577

578

579

580

581

582

583

584

585

586

587

588

Proteomics. Anal Chem. American Chemical Society; 2003;75: 663-670.

doi:10.1021/ac026117i

39. Rajala N, Hensen F, Wessels HJCT, Ives D, Gloerich J, Spelbrink JN. Whole cell formaldehyde cross-linking simplifies purification of mitochondrial nucleoids and associated proteins involved in mitochondrial gene expression. PLoS One. Public Library of Science; 2015;10: e0116726. doi:10.1371/journal.pone.0116726

40. Cox J, Mann M. MaxQuant enables high peptide identification rates, individualized p.p.b.range mass accuracies and proteome-wide protein quantification. Nat Biotechnol. 2008;26: 1367-72. doi:10.1038/nbt.1511

41. Sloothaak J, Odoni DI, de Graaff LH, Martins Dos Santos VAP, Schaap PJ, TamayoRamos JA. Aspergillus niger membrane-associated proteome analysis for the identification of glucose transporters. Biotechnol Biofuels. 2015;8: 150. doi:10.1186/s 13068-015-0317-9

42. Vizcaíno JA, Csordas A, Del-Toro N, Dianes JA, Griss J, Lavidas I, Mayer G, PerezRiverol Y, Reisinger F, Ternent T, Xu QW, Wang R, Hermjakob H. 2016 update of the PRIDE database and its related tools. Nucleic Acids Res. Oxford University Press; 2016;44: D447-D456. doi:10.1093/nar/gkv1145

43. Claudel-Renard C, Chevalet C, Faraut T, Kahn D. Enzyme-specific profiles for genome annotation: PRIAM. Nucleic Acids Res. 2003;31: 6633-9. Available:

http://www.pubmedcentral.nih.gov/articlerender.fcgi?artid=275543\&tool=pmcentrez\&ren dertype $=$ abstract

44. Kanehisa M, Goto S. KEGG: kyoto encyclopedia of genes and genomes. Nucleic Acids Res. 2000;28: 27-30. Available:

http://www.pubmedcentral.nih.gov/articlerender.fcgi?artid=102409\&tool=pmcentrez\&ren dertype=abstract

45. Kanehisa M, Sato Y, Kawashima M, Furumichi M, Tanabe M. KEGG as a reference resource for gene and protein annotation. Nucleic Acids Res. 2015;44: D457-62. doi:10.1093/nar/gkv1070

46. R Core T. R: A language and environment for statistical computing. [Internet]. R Foundation for Statistical Computing, Vienna, Austria.; 2014. Available: http://www.rproject.org/

47. Cao N, Du J, Gong CS, Tsao GT. Simultaneous Production and Recovery of Fumaric Acid from Immobilized Rhizopus oryzae with a Rotary Biofilm Contactor and an Adsorption Column. Appl Environ Microbiol. 1996;62.

48. Lin MS, Wang HH. Anaerobic growth and oxygen toxicity of Rhizopus cultures isolated from starters made by solid state fermentation. Zhonghua Min Guo Wei Sheng Wu Ji Mian Yi Xue Za Zhi. 1991;24: 229-39. Available: http://www.ncbi.nlm.nih.gov/pubmed/1855404

49. Weusthuis RA, Visser W, Pronk JT, Scheffers WA, van Dijken JP. Effects of oxygen limitation on sugar metabolism in yeasts: a continuous-culture study of the Kluyver effect. Microbiology. 1994;140 ( Pt 4: 703-15. doi:10.1099/00221287-140-4-703

50. Felig P. The glucose-alanine cycle. Metabolism. 1973;22: 179-207. doi:10.1016/00260495(73)90269-2

51. Feillet F, Leonard J V. Alternative pathway therapy for urea cycle disorders. Journal of Inherited Metabolic Disease. Kluwer Academic Publishers; 1998. pp. 101-111. doi:10.1023/A:1005365825875 
$58952 . \quad \mathrm{Gu} \mathrm{S}, \mathrm{Xu} \mathrm{Q}$, Huang H, Li S. Alternative respiration and fumaric acid production of Rhizopus oryzae. Appl Microbiol Biotechnol. 2014;98: 5145-52. doi:10.1007/s00253014-5615-9

53. Vanlerberghe GC. Alternative oxidase: a mitochondrial respiratory pathway to maintain metabolic and signaling homeostasis during abiotic and biotic stress in plants. Int J Mol Sci. Multidisciplinary Digital Publishing Institute; 2013;14: 6805-47. doi:10.3390/ijms14046805

54. Johnson MA, Vidoni S, Durigon R, Pearce SF, Rorbach J, He J, Brea-Calvo G, Minczuk M, Reyes A, Holt IJ, Spinazzola A. Amino acid starvation has opposite effects on mitochondrial and cytosolic protein synthesis. PLoS One. Public Library of Science; 2014;9: e93597. doi:10.1371/journal.pone.0093597 